\title{
Responsible reduction of nitrates in the comprehensive water cycle
}
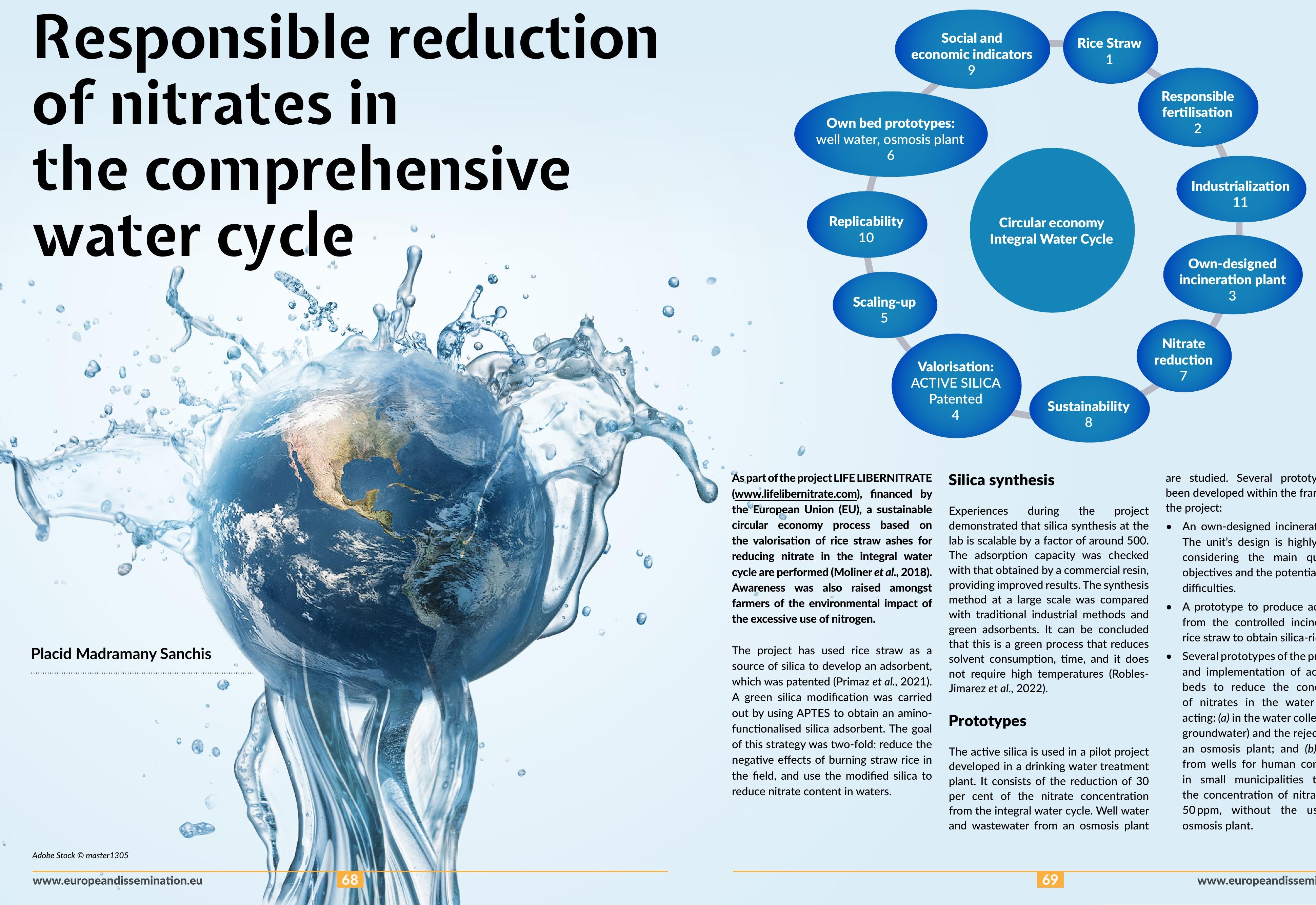

As part of the project LIFE LIBERNITRATE Silica synthesis (www.lifelibernitrate.com), financed by the European Union (EU), a sustainable circular economy process based on the valorisation of rice straw ashes for reducing nitrate in the integral water cycle are performed (Moliner et al., 2018) Awareness was also raised amongst farmers of the environmental impact of the excessive use of nitrogen.

The project has used rice straw as a which was patented (Primaz et al., 2021). A green silica modification was carried out by using APTES to obtain an aminofunctionalised silica adsorbent. The goa of this strategy was two-fold: reduce the negative effects of burning straw rice in the field, and use the modified silica to reduce nitrate content in waters. Experiences during the project demonstrated that silica synthesis at the The adsorption a factor of around 500 .

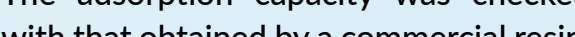
providing improvedresuls. The syaresin proving improvedresuls. The synthesis green adsorbents. It can be concluded that this is a green process that reduces solvent consumption, time, and it does not require high temperatures (Robles-

Prototypes

The active silica is used in a pilot project developed in a drinking water treatment plant. It consists of the reduction of 30 per cent of the nitrate concentration from the integral water cycle. Well water and wastewater from an osmosis plant are studied. Several prototypes have been developed within the framework of the project:

An own-designed incineration plant. The unit's design is highly bespoke, considering the main quantitative objectives and the potential technical difficulties.

- A prototype to produce active silica from the controlled incineration of rice straw to obtain silica-rich ash.

Several prototypes of the preparation and implementation of active silica beds to reduce the concentration of nitrates in the water cycle by acting: (a) in the water collector (from groundwater) and the reject water of an osmosis plant; and (b) in water from wells for human consumption in small municipalities to reduce the concentration of nitrates below $50 \mathrm{ppm}$, without the use of an osmosis plant. 

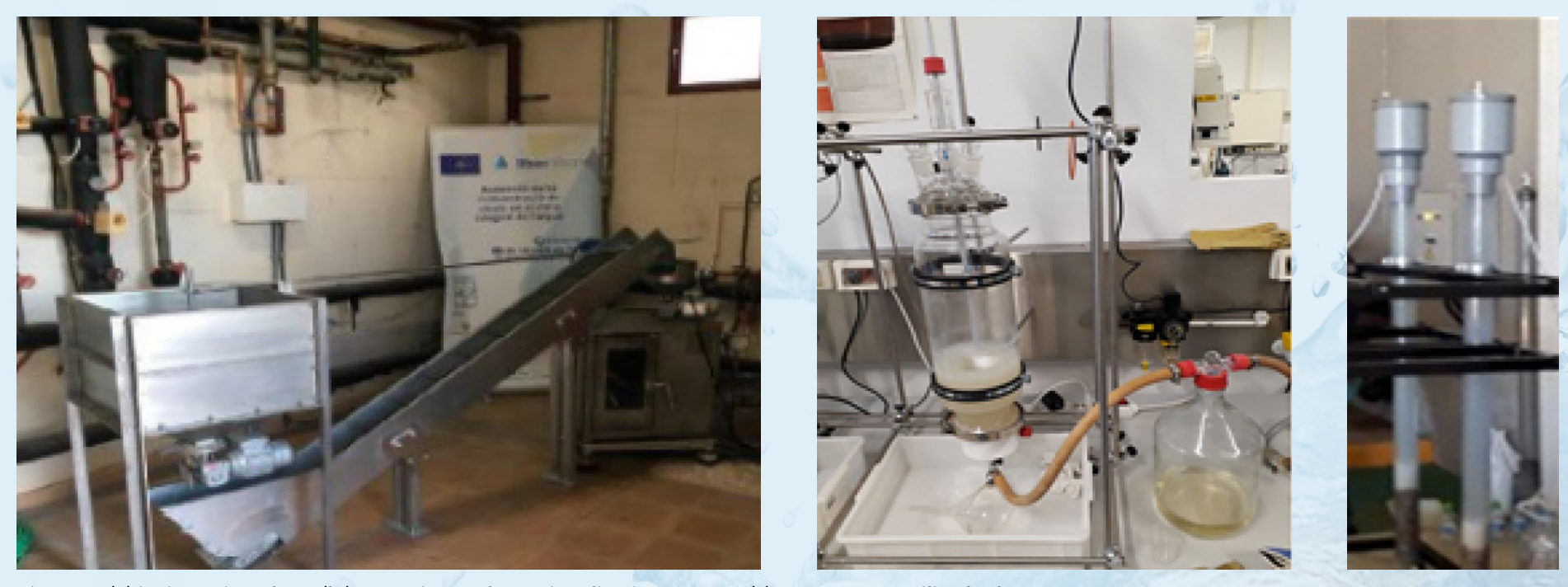

Figure 1: (a) incineration plant; (b lextraction and functionalisation reactor; (c) prototypes of silica beds.

Figure 1 shows (a) the incineration plant comprises four elements: storage, conveyor belt, incineration unit and gas treatment section, (b) extraction and functionalisation reactor, and (c) prototypes of silica.

Several controls are used in the different elements of the plant: (i) temperature controllers-inlet air, combustion chamber, outlet gas, ash container, (ii) feeding inlet flow and belt velocity; and (iii) volumetric flow-inlet air and outlet gas. All these variables are monitored through controller that can work automatically following defined working conditions. All the system elements follow a fail-safe criterion to ensure they remain in the most secure form in case of failure.

Pellets enter the combustion chamber from the dosing silo through the feeding tube regulated by a rotary valve (Moliner, Bove and Arato, 2020). Air is conveyed from the outside into the combustio chamber through an air conveyor. Inside this chamber, on its back surface, two ignition glow plugs (250w each) are ignition glow plugs (250W each) are the combustion chamber, a smoke fan is installed with a dual functione (i) is installe with a dual function: (i) extract the fumes from the combustion chamber towards the outside; and (ii) ensure air e.ty A Aox (length $=0.19 \mathrm{~m}$ widh $=0.304 \mathrm{~m}$, height $=0.094 \mathrm{~m}$, for a total volume $0.0055 \mathrm{~m}^{3}$ ) is placed at the chamber's bottom to collect the ashes produced during combustion. The chamber is closed with an isolated door with a glass window to observe the flame and visually control the process. Four temperature sensors are placed inside the chamber (top, gas outlet, hearth of the combustion chamber and ashes collector) whose

\section{Demonstration and testing}

Throughout the project, demonstration and testing tasks of the active silica beds, for the retention of nitrates in the water treatment plant of the Alginet municipality, have taken place. This includes verification of the correct operation on artisan manufacturing silica, glass and Teflon. We worked on them with different configurations, series and parallel, working two or more filters with these configurations and individually on each prototype. This first prototype allowed, by design, to observe the behaviour of the water when it came into contact with the silica-gel, to observe the behaviour of the flow of the fluid inside it, so that, throughout various tests, it was possible to optimise flow rates, and work pressures.

Other prototypes used fibre bottles, the type used in ion exchange. This industrialised equipment allowed work with higher flow rates and pressures, equipment, with different beds of gravel/ having a more stable behaviour with different working modes. Likewise, the fluid inlet and outlet system ensures a greater permanence of the silica-gel within the container itself, reducing turbidity to values that allow continuous measurement with nitrate measurement equipment. At this point, the system is partially automated. Right now, it is not necessary to disconnect and/ or connect pipes to exchange the processes of activation of the silica-gel or denitrification of the water. The flow can directed towards the desired process via an electrical panel that controls various selectors and a series of solenoid valves.

With the application of existing daptation systems on the market, industrialisation and implementation are facilitated, leaving some fringes such as higher level of process automation, a a hisher trigger times

\section{Actions}

During the four years of implementation of the LIBERNITRATE project and within the sub-action dedicated to raising farmers' awareness of the environmental impact of the excessive use of nitrogen fertilisers, the following actions have

Fertilisation of three plots dedicated to the cultivation of persimmon, citrus, and rice with slow-release fertilisers. The results show a reduction in the consumption of nitrogen fertilisers of more than 20 per cent with no reduction in production.

2. Development of an online self-trainin course on responsible fertilisation nitrate vulnerable areas. This cours aims to overcome the general lack knowledge about this problem in the agricultural community and highlight the importance that reducing nitroge fertilisation will have in practice after the new EU Common Agricultura Policy.

This course is divided into six modules in video format in Spanish, Italian and English (with subtitles in other languages) which can be watched independently. It is available on the project's Youtube channel.

\section{The course modules are:}

1. Fertilisation: basic notion

2. The Nitrates Directive and Vulnerable Zones

3. Nitrogen determination in soil

4. The New Common Agricultural Policy: good agricultural practices

5. The fertilisation programme

6. Practical cases of responsible fertilisation: the LIBERNITRATE project.

\section{Impact measurement}

Finally, the key indicator to measure the project's socio-economic impact

the project's socio-economic impact

\section{References}

Moliner, C., Teruel-Juanes, R., Primaz, C., Badia, J., Bosio, B., Campíns-Falcó, P., Molins-Legua, C., Hernandez, F., Sanjuan-Navarro, L., Madramany, P., Morán, ,.., Castro, J., Sanchis, F., Martínez, J., Hiddini, F., Ribes-Greus, A. and Arato, E. (2018) 'Reduction of Nitrates in Waste Water through the Valoriza
Rice Straw: LIFE LIBERNITRATE Project', Sustainability, 10(9), 3007. doi: 10.3390/su10093007. Moliner, C., Bove, D. and Arato. E. (2020) 'Co-Incineration of Rice Straw-Wood Pellets: A Sustainable Primaz, C.T., Jornet-Martinez, N., Sanjuan-Navarro, L., Moliner-Estopiñan, C., Campins-Falcó, P., Molins-
Legua, C. Ribes-Greus, M.D., Badia-Valiente, J.D., Teruel-Juanes, R., Gil-Castell, O., Bosio, B. and Arato, E. (2021) Procedidiento de odsón arroz. Spanish Patents and Trade Mark Office Patent no. E2727673 B2

Robles-Jimarez, H.R., Sanjuan-Navarro, L., Jornet-Martinez, N. Primaz, C.T. Teruel-Juanes, R., MolinsLegua, C., Ribes-Greus, A. and Campins-Falcó, P. (2022) 'New silica based adsorbent material from rice straw and its in-flow application to nitrate reduction in waters: Process sustainability and scale-up possibilities' Science of Total Environment, 805, 150317. doi: 10.1016/j.scitotenv.2021.150
PROJECT NAME

Life Libernitrate

PROJECT SUMMARY PROJECT SUMMARY of nitrates in the comprehensive water cycle.

PROJECT LEAD AVSA is a private company specialised in DIVAL is a public entity that represents the 266 municipalities of the province of LWlicicia. the UNIGE is a public university that participat
through its DICCA research groups. UNIO is a professional agricultural ranchers of the Valencian Community UPV is a public university that participate through its DREMAP research groups. through its MINTOTA and ECON research

PROJECT PARTNERS

A total of eight public-priva

the consortium that develops the LIFE Stichting Incubator (LWI), Università degl.
Studi di Genova (UNIGE), La Unió de Llauradors i Ramaders del Paísd Valencià
(UNIO), Polytechnic University of Valencia (UNIO), Polytechnic University of Valen CONTACT DETAILS

Placid Madramany Sanchis
Ed. Polivalent Verge de la Salut

C/ de la Safor, 22, 46680 Algemesí - Spain Iit +34962424641
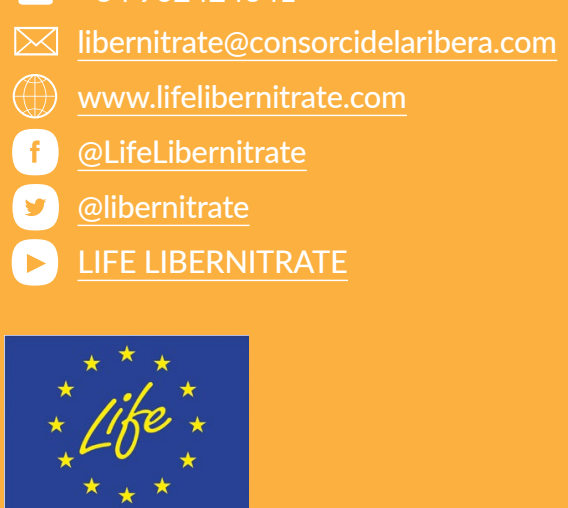

=UNDING

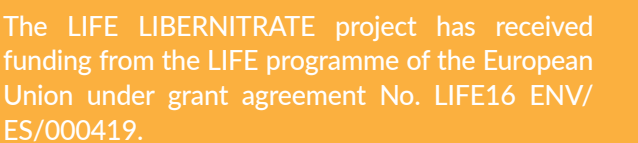
funding from the LIFE programme of the European
Union under grant agreement No. LIFE16 ENV/

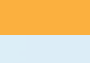

www.europeandissemination.eu 